\title{
Anomalous Changes in Geomagnetic Field on Oosima Volcano Related with Its Activities in the Decade of 1950
}

\author{
By \\ Izumi YoKoYAMA \\ Geophysical Institute, Hokkaido University
}

\begin{abstract}
At Oosima Volcano, Izu, various geomagnetic studies have been continued since its great eruption of 1950-51. And also the results of geophysical and geological investigations of the structure of Oosima Volcano have been accumulated. In 1957, the present author discussed the anomalous change in geomagnetic field observed in the 1953-54 eruption. In the present paper the author would revise this discussion reflecting upon the results of 10 years' observation of magnetic declination and the accumulated results of the subsurface structure of the volcano. The conclusion is that the observed anomalous changes are interpretable by the possible thermal processes beneath the volcano. Its quantitative results on heat supply to the volcano may lend a suggestion as to energetics of volcanisms.
\end{abstract}

\section{§1. Introduction}

The researches of the changes in geomagnetic field accompanied by volcanic eruptions as well as those by earthquakes have been one of the aims of the geomagnetic surveys throughout Japan which were commenced by A. TANAKadate in 1893 . Many observational data accumulated since that time have given a large effect on the images of physical mechanisms and energetics of volcanic activities in this country. Already the present author [1966] reviewed many examples of the observations during the past 70 years and the interpretations for them. At the time of the 1940 great eruption of Miyake Volcano, a few geophysicists observed the anomalous changes in geomagnetic field independently each other. These observations convinced Japanese geophysicists that the geomagnetic changes accompanied by volcanic activities might be expected on basaltic volcanoes such as Miyake and Oosima Volcanoes, Izu.

Concerning the 1950 great eruption of Oosima Volcano, Rikitake [1951] made the geomagnetic studies at its early stage: from the observations of the changes in magnetic dip, he deduced that a spherical part of about $2 \mathrm{~km}$ in diameter at a depth of about $5.5 \mathrm{~km}$ beneath the volcano was heated above the Curie temperature and lost its

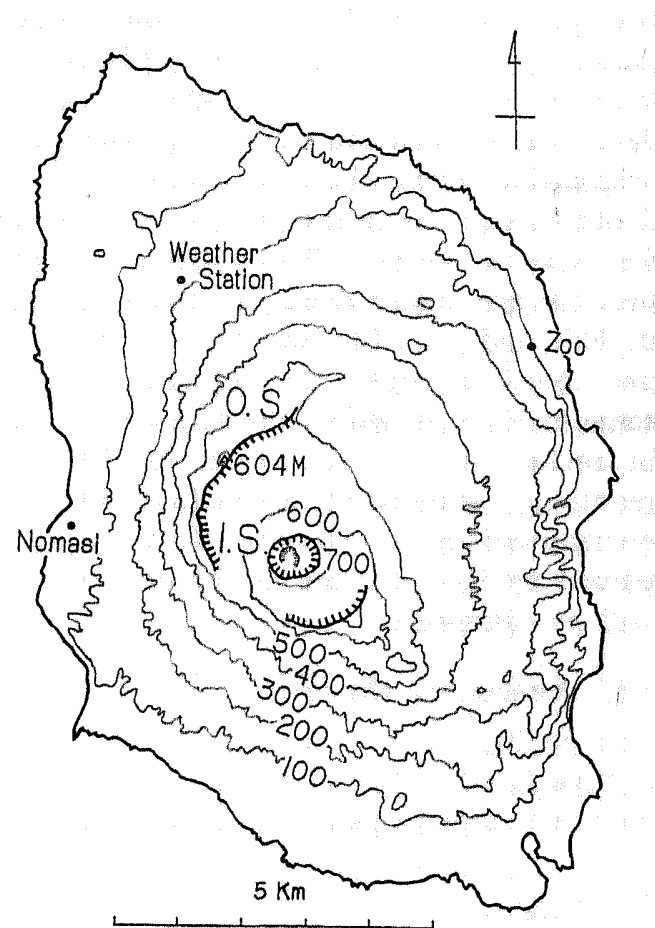

Fig. 1. Topographic map of Oosima Island. Contour interval is 100 meters.

magnetization. Since 1951, a continuous observation of the changes in geomagnetic declination has been made at Nomasi, the western coast of Oosima Island. At the time of a moderate eruption in $1953 \sim 54$, the author 
[1956a] analyzed the anomalous changes in declination observed at Nomasi toghther with the changes in dip at the summit and discussed the probable thermal processes in connection with the volcanic activities. In this discussion, it was necessary to assume a certain condition in order to interprete the recovery of magnetization due to cooling of rock-mass beneath the volcano for a rather short period (5 months).

Upon reflection, it may be probable that the surface phenomena of volcanic activities would be not always simultaneous with the thermal processes at the depth of volcanoes which are to be deduced from the observations of anomalous changes in geomagnetism. Generally speaking, thermal processes beneath volcanoes would have a relation with the geomagnetic changes of long periods. According to this idea, we may discriminate long period changes from short ones and detect the anomalous changes in geomagnetism originating from thermal processes at the depth by examining the geomagnetic changes for several years. The changes of short periods are "superposed on those of longer periods and probably are due to the shallow and local origins, for an example, piezomagnetism caused by the changes of stress in rocks. In this report, from the abovementioned standpoint, anomalous changes in geomagnetism on Oosima Volcano accompanied by its activities in the decade of 1950 will be discussed.

\section{$\S 2$. Anomalous changes}

Since 1951, the continuous observation of declination has been carried out at Nomasi on the western coast of the island in order

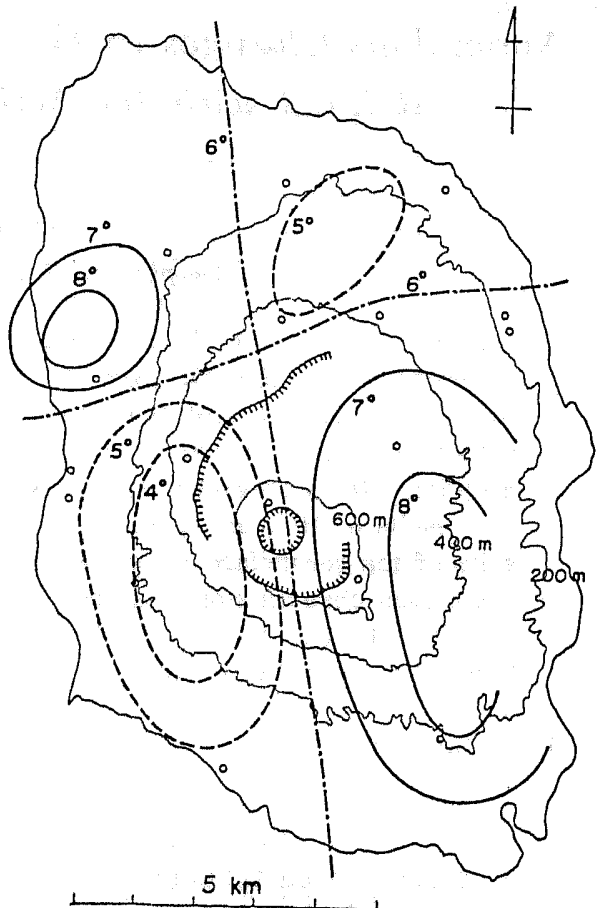

Fig. 2. Distribution of the westerly declination for 1956.0 on Oosima Island.

to detect the relation between volcanic activities and geomagnetic changes. This observation point is deemed adequate for the purpose because declination there is expected to be prone to change in connection with the changes of magnetization of the volcano as seen from the distribution of declination on Oosima shown in Fig. 2. The magnetometer which has a magnet suspended with a fine phosphor-bronze ribbon is installed in a cave. The semi-monthly means obtained from hourly values and from daily means successively are plotted in Fig. 3 . In the

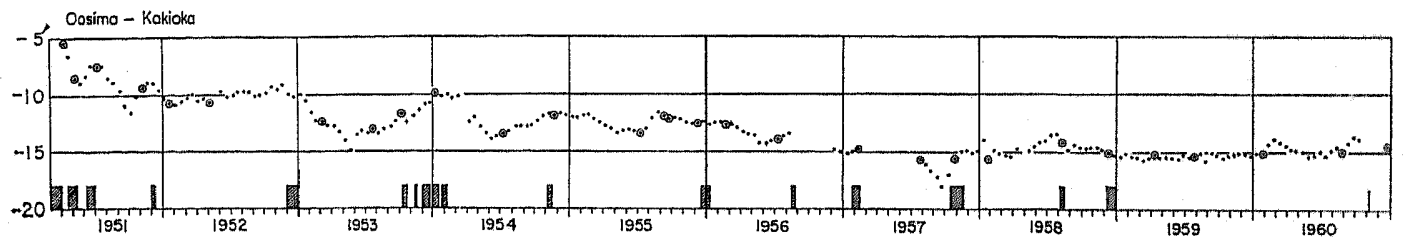

Fig. 3. Variation of the difference of the semi-monthly mean of the westerly declination between Oosima and Kakioka. Double circles denote the values calibrated by the absolute measurements. Hatched columns denote the active periods. 
figure, also the active periods of the volcano are shown by the hatched columns, but the 1950-51 eruption was very large comparing with the other activities: about $5 \times 10^{7}$ ton of lavas were erupted by this eruption and about $1 \times 10^{6}$ ton of lavas by the $1953-54$ eruption. The data of the continuous observation after 1957 are given by Yukutake and Yabu [1962]. In the figure, the differences between Nomasi and Kakioka Magnetic Observatory which is situated at a distance of $180 \mathrm{~km}$ north-east from Oosima, are obtained in order to eliminate the effects of geomagnetic disturbances of outer origin. Declination at Nomasi has changed eastward after the climax of the eruption in 1951, repeating small oscillatory changes and reached asymptotically a certain level about 1957. The double circles in Fig. 3 denote the semi-monthly means which are calibrated by the absolute observations by means of a G.S.I. (Geographical Survey Institute) type magnetometer. Determinations of the declination values are based upon the observations of the Polaris and their accuracy is 0.1 minute of arc. The base-lines on the magnetograms are recorded by reflections from a small fixed mirror beside the magnet system and therefore, strictly speaking, are liable to suffer from unaccountable drifts. To mention the most reliable values of Fig. 3, they are the double circles and shown in Fig. 4 to see more clearly.

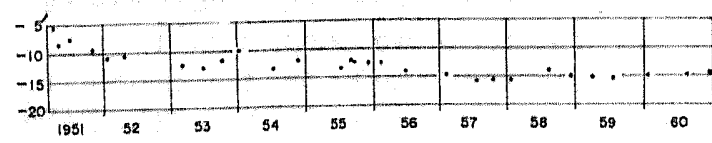

Fig. 4. Variation of the difference of the semimonthly mean of the westerly declination between Oosima and Kakioka. All are calibrated by the absolute measurements.

As seen in these figures, since 1951, several changes in geomagnetic declination have been observed. Two of them were already analyzed by the present author [1954, 1956a]. Their results are summarized in Table 1 where the third is that of the present discussion. The first is the result of comparison of the changes in geomagnetic three com-
Table 1. Examples of the anomalous changes in geomagnetism on Oosima analyzed by the author.

\begin{tabular}{c|r|r|r|r}
\hline Epoch & $\begin{array}{c}\text { Depth of } \\
\text { Dipole } \\
(\mathrm{km})\end{array}$ & $\begin{array}{c}\text { Moment } \\
\text { of Dipole } \\
\text { (emu) }\end{array}$ & $\begin{array}{c}\text { Dura- } \\
\text { tion } \\
\text { (year) }\end{array}$ & $\begin{array}{c}\text { Observa- } \\
\text { tion }\end{array}$ \\
\hline $1951 \sim 53$ & ca. 4 & $9 \times 10^{18}$ & 2 & 3 Comp. \\
$1953 \sim 54$ & 1.6 & $1.2 \times 10^{18}$ & 1 & Decli. \& Dip \\
$1951 \sim 57$ & $1 \sim 2$ & $3 \times 10^{18}$ & 6 & Decli. \& Dip \\
\hline
\end{tabular}

ponents observed at 10 posts in 1951 and 1953. Its approximation by a dipole is not so adequate: the dipole is situated at the outside of the caldera and magnetized vertically downward. The second is concerned with the westward change in declination and its recovery observed during 1953 to 1954 . The dipole is determined by both the changes in declination and in dip simultaneously observed at the summit, on the assumption that it is magnetized in the direction of the present geomagnetic field.

Now we are going to consider again the secular changes in declination during the period 1951 to 1960 shown in Fig. 3. In the figure, the westward and eastward changes of short periods are superposed on the gradual eastward change for about 7 years. If we take this gradual change as a standard, the first two changes in Table 1 become smaller in amplitude and some parts of them may be due to local origins, e.g. piezomagnetic changes caused by stress changes. It may be concluded that the declination at the western coast changed gradually about 7 minutes of arc eastward for 6 years 1951 to 1957 as the aftereffects of the 1950-51 eruption. Taking into consideration the difference of the rate of the secular changes in declination between Oosima and Kakioka, i.e. 0.25 and 0.15 minutes of arc per year for 1950 and 1960 respectively according to the G.S.I., we may say that the anomalous change amounts about 5.5 minutes of arc/6 years.

If we approximate the change in geomagnetic field during 1951 to 1957 by a dipole field, we may determine its moment and depth only by knowing the distributions of the three geomagnetic components all over Oosima Island both in 1951 and 57. However, 
we had no such observations in 1957 and therefore, we shall analyze the declinations and dips observed at Nomasi at both the epochs because the measurements of angles are usually more accurate than those of intensities by a G.S.I. type magnetomater. With regards to the changes in declination, they are already described above. The results of the measurements of dip at Nomasi in 1951 and 1957 are summarized as follows:

$\begin{array}{llll}\begin{array}{l}\text { May 9, } 1951 \\ \text { (mean of } 5 \text { meas- } \\ \text { ur.) }\end{array} & \text { Nomasi } & \text { Kakioka } & \text { Diff. } \\ \begin{array}{c}\text { ur } 22.0^{\prime} \\ \text { July 22 \& } 23,1957\end{array} & 49^{\circ} 22.6^{\prime} & -2^{\circ} 00.6^{\prime} \\ \begin{array}{c}\text { (mean of } 10 \text { meas- } \\ \text { ur.) }\end{array} 47^{\circ} 14.5^{\prime} & 49^{\circ} 15.6^{\prime} & -2^{\circ} 01.1^{\prime}\end{array}$

Thus the anomalous change at Nomasi, Oosima Island amounts to $-0.5^{\prime} / 6$ years. On the other hand, the difference of the rate of secular variations between Oosima and Kakioka is $+0.2^{\prime}$ and $-0.1^{\prime}$ year for 1950 and 1960 respectively according to the G.S.I. For 6 years from 1951 to 1957, the difference amounts about $0.5^{\prime}$. Therefore, after the correction, the anomalous change in dip is $-1.0^{\prime}$ /years.

For the purpose to find the moment and depth of the dipole corresponding to the above anomalous changes, we shall take the origin of the Cartesian co-ordinates at the point on sea level and just above the dipole. Then the three components at observation point $(x, y)$ are expressed as follows:

$$
\begin{aligned}
& \Delta D=\tan ^{-1} 3 M \sin \theta \frac{y}{r^{5}}\left(\frac{x}{Z_{0}}-\frac{d}{H_{0}}\right), \\
& \Delta H=-M \cos \theta\left(d^{2}-2 x^{2}-y^{2}-3 x d \frac{Z_{0}}{H_{0}}\right), \\
& \Delta Z=-M \sin \theta\left(x^{2}-2 d^{2}-y^{2}-3 x d \frac{H_{0}}{Z_{0}}\right),
\end{aligned}
$$

where $M$ denotes the moment, $d$ the depth, $r$ the distance between the dipole and the observation point, and $\theta$ dip-angle. If we define the following function

$$
f(\Delta I)=\frac{\tan \left(I_{0}+\Delta I\right)-\tan I_{0}}{\tan I_{0}},
$$

we get

$$
f(\Delta I)=\frac{\Delta Z}{Z_{0}}-\frac{\Delta H}{H_{0}}
$$

Now, for the sake of simple estimation, we assume $H_{0} \div Z_{0}$ at the middle latitude. Then we get

$$
\begin{aligned}
\Delta D & =\frac{3 M}{F_{0} r^{5}}(x-d) y, \\
f(\Delta I) & =-\frac{3 M}{F_{0} r^{5}}(x-d)(x+d),
\end{aligned}
$$

where $F_{0}$ denotes the total force. In the above equations, the unknowns are $M, x$ and $d$ while the left-hand sides are known. At Nomasi, $\Delta D=1.6 \times 10^{-3}$ radian and $f(\Delta I)=0.6$ $\times 10^{-8}$ and $y$ is assumed as $-3.4 \mathrm{~km}$. Substituting these values into eq. (5) and (6), we get

$$
x+d=1.3(\mathrm{~km}) .
$$

If the dipole is situated just below the centre of the volcano, namely $x=0$ and $y=$ $-3.4 \mathrm{~km}$, the depth $d$ equals to $1.3 \mathrm{~km}$, and the moment $M$ is $3.3 \times 10^{18} \mathrm{emu}$.

On the other hand, the extrapolated rates of the secular variations to the anomalous areas such as Oosima Island arouse a question: the above small change in dip $-0.5^{\prime} / 6$ years may be attiributable to the difference of the general secular variations, not to volcanic origins. Then it may be concluded that there had been no anomalous changes in dip related with volcanic activities during that period. Substituting $\Delta D=1.6 \times 10^{-8}$ radian and $f(\Delta I)=0$ into eq. (5) and (6), we get $x=-d$; in other words, the dipole is situated at the distance $\bar{d}$ northward and $\bar{y}$ eastward from Nomasi. If we adopt that the dipole is beneath the interior of the caldera, the value of $d$ should be probably $1 \sim 2 \mathrm{~km}$. For the above anomalous changes, we get the moment of the dipole as $2.9 \times 10^{13}$ and $3.4 \times 10^{13}$ emu on the assumption $d=-x=1$ and $2 \mathrm{~km}$ respectively.

Anyway, the depth of the dipole is $1 \sim 2$ $\mathrm{km}$ and its moment is of the order of $3 \times 10^{18}$ emu. As already discussed by the present author [1967b], the magnetic dipole which approximates the geomagnetic anomalies observed on Oosima Volcano, is situated at the depth of about $2 \mathrm{~km}$ below sea level at the centre of the island and has the moment of about $7.1 \times 10^{14} \mathrm{emu}$. The above dipole in- 
terpreting the anomalous changes for the period 1951 to 1957 , is about $4 \%$ in the moment of that corresponding to the geomagnetic anomaly there.

\section{§3. Interpretation}

As for the origin of the anomalous changes in geomagnetism at volcanoes, the following two are conceivable: Magnetization or susceptibility changes due to the local changes in temperature and due to the local accumulation of stress beneath the volcanoes. At some cases, both the aboves may superpose each other. Since the magnetic properties of the igneous rocks have wide varieties, possibility of geomagnetic changes is different at each volcano according to its rock-composition. It is roughly summarized as Table 2. In this table, it is noticeable that the N.R.M.
Table 2. Physical conditions at various volcanoes.

\begin{tabular}{l|c|c|c|c|c}
\hline Volcano & $\begin{array}{c}\text { N.R.M. } \\
\text { emu/cc }\end{array}$ & $\begin{array}{c}\text { Vis- } \\
\text { cosity }\end{array}$ & $\begin{array}{c}\text { Oepth } \\
\text { Ofigin } \\
\text { of } \\
\text { Ac- } \\
\text { tivities }\end{array}$ & $\begin{array}{c}\text { Ther- } \\
\text { mal } \\
\text { Effect } \\
\text { (Heat } \\
\text { Trans- } \\
\text { fer) }\end{array}$ & $\begin{array}{c}\text { Stress } \\
\text { Effect } \\
\text { (Stress } \\
\text { Ac- } \\
\text { cum.) }\end{array}$ \\
\hline Dacitic & $10^{-4}$ & large & deep & small & large \\
Andesitic & $10^{-8}$ & med. & med. & med. & med. \\
Basaltic & $10^{-2}$ & small & shallow & large & small \\
\hline
\end{tabular}

(natural remanent magnetization) of basalt is far larger than those of andesite and dacite. The N.R.M. of the igneous rocks is almost all the T.R.M. (thermal remanent magnetization). The chemical compositions of the 1950 lavas of Oosima are given by Morimoto and Ossaka [1957] as shown in Table 3. The Curie temperature of the lavas is $580^{\circ} \mathrm{C}$

Table 3. Chemical composition of 1950 lavas of Mihara after Morimoto and Ossaka.

\begin{tabular}{c|c|c|c|c|c|c|c|c|c|c|c|c}
\hline $\mathrm{SiO}_{2}$ & $\mathrm{Al}_{2} \mathrm{O}_{3}$ & $\mathrm{Fe}_{2} \mathrm{O}_{3}$ & $\mathrm{FeO}$ & $\mathrm{MgO}$ & $\mathrm{CaO}$ & $\mathrm{Na}_{2} \mathrm{O}$ & $\mathrm{K}_{2} \mathrm{O}$ & $\mathrm{H}_{2} \mathrm{O}+$ & $\mathrm{H}_{2} \mathrm{O}-$ & $\mathrm{TiO}_{2}$ & $\mathrm{P}_{2} \mathrm{O}_{5}$ & $\mathrm{MnO}$ \\
\hline 52.30 & 15.50 & 2.96 & 10.26 & 4.64 & 9.65 & 1.61 & 0.33 & 0.70 & 0.21 & 1.49 & 0.09 & 0.10 \\
\hline
\end{tabular}

and their T.R.M.s are very strong because of their large coercive force. Table 2 suggests that anomalous changes in geomagnetism accompanied by activities of the basaltic volcanoes may be probably due to temperature changes beneath the volcanoes not due to stress changes, because temperature of the lava flows reaches to as high as $1000^{\circ} \mathrm{C}$ and stress accumulation is not so large. As for the effect of compressional stress on the magnetization of the Mihara lavas, Ohnaka and Kinoshita [1968] obtained the following value:

$$
\frac{d}{d P}\left(\frac{J}{J_{0}}\right)=-9.0 \times 10^{-2} / \mathrm{kbar}
$$

where $J_{0}$ is intensity of N.R.M. at pressure $P=0$. This effect can not interprete quantitatively the anomalous changes during 1951 to 1957 , because, generally speaking, pressures of volcanic eruptions are order of 100 atm. at the highest even at andesitic volcanoes such as Asama and Tokati, and the lavas of Oosima Volcano are too fluidal at high temperature to accumulate stress within the volcano.

At Oosima Volcano, in advance to or simultaneously with the surface activities of central cone Mihara in 1950, the temperature of the subsurface rocks probably might have increased, but the processes were not all clear. According to Rikitake [1951], as mentioned before, dip increased by 30 minutes of arc at the maximum in the summit region during 2 months from July to September, 1950. Analyzing this result, he deduced that a spherical part of about $2 \mathrm{~km}$ in diameter at a depth of $5.5 \mathrm{~km}$ beneath the centre of the island became of high temperature above the Curie point and lost the magnetization of which dipole-moment is as large as $6 \times 10^{14}$ emu but he did not refer to the thermal processes in detail.

In the following, let us discuss the cooling process by which the dipole at a depth of $1 \sim 2 \mathrm{~km}$, corresponding to the change 5.5 minutes of arc in declination, can acquire 
the moment of $3 \times 10^{13} \mathrm{emu}$ during 6 years. Generally speaking, when we can interprete the cooling process, the interpretation for the heating process may be easier.

If we assume that the normal temperature at a depth of $1 \sim 2 \mathrm{~km}$ beneath this volcano is $150^{\circ} \mathrm{C}$ and it had been elevated not so much, say by $100^{\circ} \mathrm{C}$ by 1951 when the activities were highest, and it recovered to the almost normal stage after 6 years as the activities declined, the rocks there would restore magnetization about $2 \times 10^{-2} \mathrm{emu} / \mathrm{g}$ according to the result of the measurement of the Oosima lavas by Nagata [1951] as shown in Fig. 5. If we substitute the above dipole

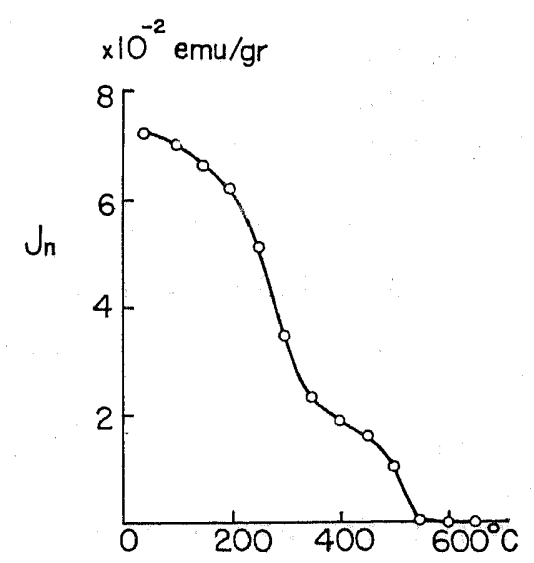

Fig. 5. Thermal remanent magnetization of the 1950 lavas of Mihara produced by the cooling process under magnetic field after Nagata.

by a sphere in the sense of a very rough approximation, its radius is $0.9 \mathrm{~km}$ and its volume amounts to $3 \times 10^{15} \mathrm{cc}$. This volume is very large as compared with that of the overflowed lavas (about $2 \times 10^{13} \mathrm{cc}$ ) but the magma which intruded into the fissures in the sphere might be not so voluminous. And its actual shape may be rather oblate vertically along the conduits and its position is approximately the same to that of the dipole interpreting the geomagnetic anomalies on Oosima Volcano as shown in Fig. 6 which was proposed by the author [1969] as a schematic structure of the volcano. Taking density and specific heat of the lavas as 2.5 $\mathrm{g} / \mathrm{cc}$ and $0.2 \mathrm{cal} / \mathrm{g}^{\circ} \mathrm{C}$ respectively, we get the

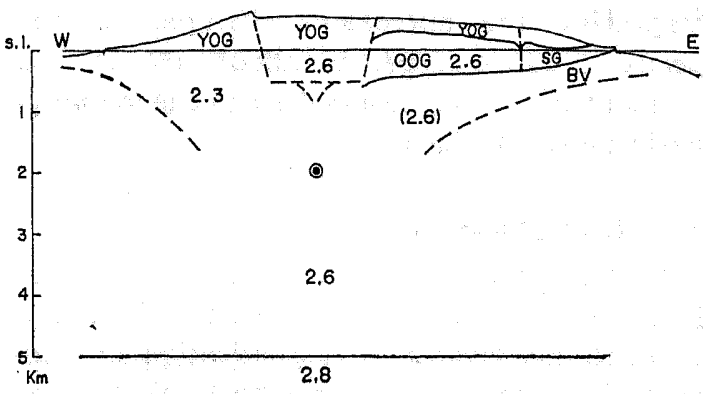

Fig. 6. Schematic section of Oosima Volcano. Double circle denotes the dipole which interpretes the geomagnetic anomalies observed on the volcano. Numerals denote density in $\mathrm{g} / \mathrm{cc}$.

YOG: the Younger Oosima Group, OOG: the Older Oosima Group, SG: Senzu Group, BV: erosion remnant of basement volcanoes.

total heat necessary to change the mean temperature of the lavas by $100^{\circ} \mathrm{C}$ as about $1.5 \times 10^{17} \mathrm{cal}$.

The activities of magma beneath the volcano would be highest almost at the same time as the highest surface activities in 1950 or 1951. For 6 years after the climax of the eruptions, the mean temperature of the lavas at that part might have recovered by nearly $100^{\circ} \mathrm{C}$. The molten magma which had filled the vents and fissures in the spherical part at the most active period, overflowed to the earth surface or retreated back to the depth and hence, the heat source of high temperature has diminished in accordance with the decline of the activities. The temperature might have decreased by $100^{\circ} \mathrm{C}$ for 6 years not only by heat conduction but by steam emission; the most probable heat source of low temperature at a depth of $1 \sim 2 \mathrm{~km}$ must be meteoric water. At Oosima Island, it rains about $300 \mathrm{~cm}$ in a year. If we assume that the rain water within the caldera (about $10 \mathrm{~km}^{2}$ in area) contacts with the lavas and evaporates, the heat absorbed for 6 years amounts to about $1.1 \times 10^{17} \mathrm{cal}$. This is approximately equal to the heat required to the cooling process as before-mentioned. The evaporated water partly expands through the crater into the air as volcanic clouds. Though a more quantitative discussion of the 
above cooling process is not impossible, it will be not completely successful because it necessarily needs a few assumptions concerning the concrete structures and physical conditions beneath the volcano. In summary, it may be safely said that the mean temperature of the spherical part corresponding to the dipole could be lowered by $100^{\circ} \mathrm{C}$ in 6 years.

\section{§4. Significance}

As discussed in the previous Section, heat energy of $10^{17} \mathrm{cal}$. ( $\approx 5 \times 10^{24} \mathrm{erg}$ ) in the order of magnitude had been dischaged since 1951 and, as the result, the conditions beneath the volcano might have almost recovered to the normal level. This energy is almost equal to that was supplied to the volcano from the deep at the time of the eruption. On the other hand, the various energies discharged by the eruptions during the period 1950 to 1954 were estimated by the present author [1956b, 57a]. They are roughly tabulated in Table 4, where potential energy is estimated from the depths of the dipoles, i.e. 2 and 1.6 $\mathrm{km}$ for the eruptions of $1950-51$ and 1953-54 respectively. As a result, we may say that almost all energy of the eruptions is heat energy transferred by lavas.

The thermal energy obtained in the previous Section was supplied to the hearth of the volcano (magma reservoir) from the deep at the time of the eruptions but its processes are not clear because we had no observations before the eruption. The various energies of the eruptions in Table 4 might have been partly defrayed by the above thermal energy and partly supplied directly from the deep. In the discussion of order of magnitude, it may be concluded that the thermal energy supplied from the deep is approximately equal in quantity to the sum of the various energies of the eruptions. In other words, the energies of the same order of magnitude as the supplied thermal energy have been discharged as the thermal energy by ejecta.

The above discussion is the only one example of basaltic volcano, Oosima; for the other volcanoes, the further verifications
Table 4. Energies released by the eruptions of Oosima Volcano.

\begin{tabular}{l|c|c}
\hline \multicolumn{1}{c|}{ Energy } & $1950-51$ & $1953-54$ \\
\hline Heat Transferred by Lavas & $9 \times 10^{23}$ & $7 \times 10^{21}$ \\
Potential Energy & $2 \times 10^{22}$ & $1 \times 10^{20}$ \\
Energy of Tremors & $2 \times 10^{18}$ & $1 \times 10^{19}$ \\
Energy of Volcanic Shocks & $2 \times 10^{18}$ & $1 \times 10^{17}$ \\
\hline Total Energy & $\sim 10^{24}$ ergs $\sim 10^{22}$ ergs \\
\hline
\end{tabular}

should be necessary. However, if we adopt the above relation for all volcanoes, we may estimate the orders of magnitude of the energies released by the past volcanic erup. tions by only knowing the temperature and volume of the ejecta. This is very noticeable in contrast to the earthquake phenomena. By the above relation, discussions of energetics of volcanic activities in geological ages may be developed. Their results will afford us a base of the quantitative discussions of origins of volcanic activities which are some of the most outstanding phenomena on the earth.

\section{References}

Morimoto, R. and J. OsSAKA:

1951 "On the Mihara-yama lavas" (in Japanese), Journ. Geograpy (Tokyo), 60, 136-140.

NAGATA, T.:

1951 "Magnetic properties of the lavas of Volcano Mihara" (in Tapanese), Journ. Geography (Tokyo), 60, 145-145.

OHNAKA, M. and H. KINOSHITA:

1963 "Effect of compressional stress on the magnetization of volcanic rocks" (in Japanese), Bull. Volc. Soc. Japan, 2 Ser., 13, 12-20.

RIKITAKE, T.:

1951 "The distribution of magnetic dip in Ooshima Island and its change that accompanied the eruption of Volcano Mihara, 1950 ", Bull. Earthq. Res. Inst., 29, 161181.

YOKOYAMA, I.:

1954 "Geomagnetic studies of Volcano Mihara, the 5th paper", Bull. Earthq. Res. Inst., 32, 169-187.

1956a "Geomagnetic studies of Volcano Mihara, the 7th paper", Bull. Earthq. Res. Inst., 34, 21-32.

1956b "Energetics in active volcanoes, 1st paper" Bull. Earthq. Res. Inst., 34, 185- 
195.

1957a "Energetics in active volcanoes, 2nd paper", Bull. Earthq. Res. Inst., 35, 7597.

1957b "Geomagnetic anomaly on volcanoes with relation to their subterranean structure", Bull. Earthq. Res. Inst., 35, 327-357.

1966 "Anomalous geomagnetic changes accompanied by volcanic activities" (in Japanese), Abstract of the 3rd Symposium, Geophys.
Inst. Tokyo Univ., 25-35.

1969 "The subsurface structure of Oosima VoIcano, Izu", Journ. Phys. Earth, 17, 5568.

YUKUTAKE, T. and T. YABU:

1962 "Geomagnetic studies on Volcano Mihara, the 9th paper", Bull. Earthq. Res. Inst., 40, 511-522.

(Received Jan 27, 1969) 